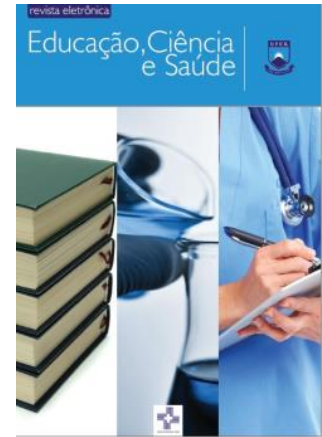

EDUCAÇÃO CIÊNCIA E SAÚDE

http://dx.doi.org/10.20438/ecs.v8i1.327

\title{
CONSULTA DE ENFERMAGEM EM PUERICULTURA: VIVÊNCIA DE MÃES NAS AÇÕES IMPLEMENTADAS
}

\author{
Julyana Falcão Madeira¹, Anny Clarisse Medeiros Freitas², Micarlla Dantas de \\ Medeiros ${ }^{2}$, Heloisy Alves de Medeiros ${ }^{3}$, Luciana Dantas Farias de Andrade ${ }^{3}$, \\ Nathanielly Cristina Carvalho de Brito Santos ${ }^{3}$. \\ 1 Enfermeira pela Universidade Federal de Campina Grande, Cuité-PB, Brasil. \\ 2 Residente em materno infantil pela Universidade Federal do Rio Grande do Norte, Santa \\ Cruz, RN, Brasil. \\ 3 Professora Unidade Acadêmica de Enfermagem, Universidade Federal de Campina Grande, \\ Cuité, PB, Brasil.
}

Email para correspondência: nathanielly.cristina@professor.ufcg.edu.br

\section{Resumo}

A consulta de enfermagem em puericultura representa uma oportunidade de avaliar a criança de forma sistematizada e individualizada levando em consideração determinantes e condicionantes de saúde, visando a promoção, proteção, recuperação e reabilitação. Objetivou-se compreender as ações implementadas na consulta de enfermagem em puericultura, a partir da vivência de mães. Pesquisa descritivaexploratória, qualitativa, realizada no período de outubro a dezembro de 2017, com 13 mães de crianças menores de dois anos cadastradas em duas unidades de saúde da família do município de Cuité-Paraíba. Os dados foram coletados a partir de entrevista norteada por roteiro semiestruturado, e descrita por meio da análise de conteúdo proposta por Minayo. A análise permitiu a construção de uma categoria temática: Vivência de mães acerca das ações realizadas na consulta de enfermagem em puericultura, alicerçada em três subcategorias: Etapas da consulta; Fragilidades e Contribuições para a integralidade do cuidado. Contudo, a consulta de enfermagem em puericultura representa uma importante contribuição para a redução de morbimortalidade infantil,entretanto, apresenta fragilidades.

Palavras-chave: Saúde da criança, Puericultura, Consulta de Enfermagem

\begin{abstract}
The nursing consultation in childcare represents an opportunity to evaluate the child in a systematized and individualized way taking into account determinants and health conditions, aiming at promotion, protection, recovery and rehabilitation. The objective was to understand the actions implemented in the nursing consultation in childcare, based on the experience of mothers. Descriptive-exploratory, qualitative research, conducted from
\end{abstract}


October to December 2017, with 13 mothers of children under two years of age registered in two family health units in the municipality of Cuité-Paraíba. Data were collected from an interview based on a semi-structured script, and described through the content analysis proposed by Minayo. The analysis allowed the construction of a thematic category: Experience of mothers about the actions performed in the nursing consultation in childcare, based on three subcategories: Stages of the consultation; Weaknesses and Contributions to the integrality of care. However, the nursing consultation in childcare represents an important contribution to the reduction of infant morbidity and mortality, however, it presents weaknesses.

Keywords: Child Health; Child Care; Nursing Consultation

\section{Introdução}

A criança, um ser em processo contínuo de crescimento e desenvolvimento, torna-se mais vulnerável ao adoecimento e morte diante da imaturidade dos sistemas e a adaptação ao contexto na qual estar inserida. Por isso, faz-se necessário o seguimento do cuidado na consulta de puericultura, como atribuição do enfermeiro da atenção primária à saúde (MONTEIRO et al. 2016).

No Brasil, a atenção à saúde da criança ganhou ênfase a partir do Programa de Atenção Integral à Saúde da Criança - PAISC, na década de 1980, objetivando promover um crescimento e desenvolvimento saudável e reduzir a morbimortalidade infantil. A criança e sua família passaram a ser acompanhadas por uma equipe multidisciplinar, com destaque para os profissionais de enfermagem, que se utilizam do conhecimento técnico acerca do processo saúde-doença e associam ás condições de vida destes usuários. Além disso, realizam uma consulta baseada no diálogo e troca de experiência, aumentando o vínculo profissional-família (GÓES et al. 2018).

Apesar disso, foi verificada a necessidade de melhorias das políticas vigentes para a garantia da integralidade em saúde da criança, tanto pelas mudanças no perfil epidemiológico e demográfico quanto pelas alterações dos determinantes e condicionantes de saúde. Nesse sentido, a Política Nacional de Atenção Integral à Saúde da Criança - PNAISC, vem com o propósito de aprimorar esse modelo de saúde, tendo como características principais o agrupamento de diretrizes, maior foco na criança e na família, na resolutividade e na oferta de um cuidado em rede (BRASIL, 2015).

Por isso o profissional deve procurar conhecer e compreender a criança de maneira holística no ambiente familiar, social, considerando as relações e interações com o contexto socioeconômico em que estar inserida, como 
princípio fundamental para alcançar o resultado esperado (PERINAZZO et al. 2015).

Nessa perspectiva, a consulta de enfermagem em puericultura é um acompanhamento periódico que visa uma ação integral, favorecendo o crescimento e desenvolvimento físico, mental, moral, aspectos biológicos, antropológicos e psicológicos da criança, lhe assegurando melhor qualidade de vida. É necessário que o enfermeiro realize todas as etapas durante a consulta de puericultura que são: histórico de enfermagem e exame físico, avaliação do crescimento e desenvolvimento, diagnóstico de enfermagem, plano terapêutico ou prescrição de enfermagem e orientações em geral (MONTEIRO et al., 2016).

No entanto, a realidade posta pela literatura ainda delimita fragilidades no que concerne a implementação da consulta de puericultura pelo enfermeiro, como evidenciou estudo no qual a formação do vínculo entre os profissionais de saúde e a comunidade, bem como o atendimento e o monitoramento do crescimento e desenvolvimento da criança ainda se apresentam incipientes diante da almejada integralidade da atenção (SOARES et al. 2016).

Ante o exposto, surgiu o seguinte questionamento: Quais as ações implementadas pelo enfermeiro na consulta de puericultura? Para responder a essa pergunta considera-se relevante o olhar da mãe ou cuidadora, uma vez que participam diretamente desse processo junto à criança. Objetivou-se compreender as ações implementadas na consulta de enfermagem em puericultura, a partir da vivência de mães.

\section{Metodologia}

Trata-se de uma pesquisa descritiva-exploratória de abordagem qualitativa, realizada em duas Unidades de Saúde da Família (USF) no município de CuitéParaíba. O município citado está localizado no Curimataú Ocidental, região semiárida, o qual possui uma população estimada em 20.348 habitantes, sendo 1.173 com até 2 anos completos ou na primeiríssima infância (IBGE, 2017).

A coleta de dados foi realizada no período de outubro a dezembro de 2017, no qual a entrevista foi guiada por meio de um roteiro semiestruturado contendo a seguinte questão disparadora: "Fale para mim como é realizada a 
consulta de puericultura do seu filho (a) na unidade de saúde da família pela enfermeira?" A seleção das participantes se deu nas unidades de saúdes no dia da puericultura, por meio da fila de espera para o atendimento, a qual seguia a ordem de chegada. As mães eram convidadas a participar da pesquisa e caso não aceitassem, era convidada a próxima, e assim sucessivamente. As mães que aceitavam participar do estudo, assinaram o Termo de Consentimento Livre e Esclarecio (TCLE), e assim, era agendada a entrevista de acordo com a disponibilidade das participantes.

Participaram da pesquisa 13 mães que atenderam aos critérios de inclusão, a saber: mãe de criança menor de dois anos de idade cadastrada na área de abrangência das referidas USF e acompanhada pelo Enfermeiro nas consultas de puericultura; e ter condições emocionais e cognitivas para responder a entrevista. Como critério de exclusão foi considerado aquela mãe cuja criança no período da coleta de dados tinha ultrapassado 3 meses da última consulta, no intuito de dirimir possível viés de memória. A coleta de dados foi encerrada por saturação, quando o material empírico adquirido começou a se repetir.

As entrevistas foram realizadas no domicílio da participante, em ambiente com privacidade, silêncio e livre de interferência externa, gravadas por aparelho mp3 player, e, posteriormente, transcritas na íntegra para maior fidedignidade do conteúdo. Para garantir o anonimato, as participantes foram identificadas por nomes de sentimentos, escolhidos por elas.

Os dados coletados foram analisados por meio da técnica de Análise de Conteúdo proposta por Minayo (MINAYO, 2006) e discutidos a luz da literatura atual pertinente. Na sua estruturação, a técnica de Análise de Conteúdo abrange três etapas: pré-análise, que compreende a leitura flutuante, constituição do corpus textual para em seguida construção das categorias; exploração do material, na qual o investigador busca encontrar categorias que são expressões ou palavras significativas em função das quais o conteúdo de uma fala será organizado; e o tratamento dos resultados obtidos e interpretação, consiste na classificação e a agregação dos dados, de acordo com a categorização presentes nas das falas dos participantes. 
O estudo atendeu aos preceitos éticos da Resolução 466/2012 do Conselho Nacional de Saúde, sendo aprovado pelo Comitê de Ética em Pesquisa com Seres Humanos do Hospital Universitário Alcides Carneiro da Universidade Federal de Campina Grande, sob parecer ํㅜㄹ.206.404, CAAE: 69888917.6.0000.5182.

\section{Resultados}

Após a análise das falas das mães e agrupamento textual, foi possível a construção de uma categoria temática: Vivência de mães acerca das ações realizadas na consulta de enfermagem em puericultura, alicerçada em três subcategorias, descritas a seguir:

\subsection{Subcategoria: Etapas da consulta}

Segundo as participantes, na consulta de puericultura a enfermeira acolhe bem a criança, investiga aspectos gerais da sua saúde, bem como realiza o exame físico e avalia o crescimento e a situação vacinal, mas de forma objetiva e rápida.

"Ela pergunta se a criança tá bem, se tá se alimentando bem, se tá com algum problema, se dorme a noite toda, a alimentação dele, pesa ele, examina ele, se eu tô precisando de alguma coisa, se ele tem alergia a alguma coisa, procedimento normal". (FORÇA)

"[...] ela manda eu tirar a roupa dela, pesa, mede a cabeça, mede o abdômen, olha o tamanho, se ela cresceu, se tem alguma queixa [...] Pergunta se a vacina tá em dias. É só isso e mais nada. Anota no caderninho". (VIDA)

"Quando eu chego lá, ela pergunta se ele tá bem. Se ele dorme bem, se alimenta, aí pesa ele, mede ele direitinho. Pergunta se tem alguma queixa, eu digo que não. Pouca coisa, demora muito pouco". (SIMPATIA)

"[...] pergunta se ele tá tomando água, dessa vez ela perguntou isso porque eu já comecei a dar o NAN a ele, ai ela perguntou se eu já estava dando água a ele, eu nem sabia que tinha que dar, ai ela me informou direitinho que precisava dar porque o leite é mais forte que o leite materno, tudo mais, ai é se as vacinas estavam em dia". (APEGO).

“[...] ela dá bastante atenção, pergunta se eu tenho dúvida, pergunta se ele teve febre, diarreia, se eu tenho queixa [...]ela examina os dentinhos, ela olha a pintinha dele, pravê se tem alguma coisa". (DENGO) 
"[...] pergunta como está sendo a etapa de adaptação, pelo fato de eu ser mãe de 1 viagem. Pergunta também se o bebê tá bem, se eu ainda estou dando leite materno ou outro tipo de leite [...] olha se tem alguma manchinha e verifica o peso [...]ela também fala que o bebe tá crescendo adequadamente, que o peso tá bom pro tamanho dele". (AMOR)

"[...] examina tudo, ele todinho, ela olha se ele tá assado, se tá com febre, se tá gripado, olha a boca dele, as unhas". (TERNURA)

$\mathrm{Na}$ análise das falas em tela, verifica-se que apesar do enfermeiro contemplar na consulta de puericultura aspectos importantes da anamnese como estado geral, alimentação e sono, bem como a presença de queixa, o exame físico tem um enfoque com inspeção de aspectos de pele, dentição e genitália. Isso sugere limitações na abordagem integral à saúde da criança, enfatizando o despreparo do enfermeiro na assistência a essa população (GÓES et al. 2018).

Esse fato merece reflexões tendo em vista que a objetividade relatada na implementação de ações durante a consulta de puericultura, tal como a rapidez do atendimento pode se justificar pelas altas demandas populacionais e até sobrecarga de atividades e responsabilidades enfrentadas pelos profissionais de enfermagem no âmbito da Atenção Primária à Saúde (APS) aliado a necessidade de manter sempre o aumento da produtividade (GOMES; SILVA JÚNIOR, 2015).

Estudo realizado na cidade de Recife em Pernambuco evidenciou que os enfermeiros enfrentam dificuldades estruturais que contribuiu para ações inadequadas nas consultas de enfermagem em puericultura, tais como estrutura deficiente, em especial na disponibilidade de instrumentos/equipamentos indispensáveis para o acompanhamento do crescimento e desenvolvimento infantil. Além da sobrecarga de trabalho e a carência de capacitação profissional (CARVALHO; SARINHO, 2016)

Diante dessa assertiva, vale ressaltar que o processo de trabalho desempenhado pelos enfermeiros pode ser classificado como desafiador e frustrante, uma vez que a Estratégia de Saúde da Família (ESF) possui alta demanda populacional, além de cobrança por resultados quantitativos, número insuficiente de profissionais, e atuação gerencial à frente da direção da 
unidade, aspectos que podem sobrecarregar o profissional e comprometer a qualidade da assistência ofertada à comunidade (MAISSIAT et al. 2015).

Neste contexto, dois achados despertam a atenção, pelo fato da avaliação do crescimento ser evidenciada em todos os relatos, direcionada pelas medidas antropométricas de peso, perímetros e comprimento, assim como da situação vacinal, o que é relevante no processo de cuidado ação realizada na puericultura. Por outro lado, é preocupante a ausência de abordagem sobre o desenvolvimento neuropsicomotor e a situação de suplementação de micronutrientes como vitamina $A$ e o sulfato ferroso, importantes para a identificação precoce de alterações no desenvolvimento, hipovitaminose A e anemia (VIEIRA, 2018).

$\mathrm{Na}$ consulta de enfermagem em puericultura o exame físico deve ser realizado de forma detalhada e completa, tendo em vista a possibilidade de detectar problemas na anamnese ou mesmo em informações advindas das mães. Esse tipo de abordagem é capaz de identificar de maneira precoce algum tipo de alteração ou modificações no crescimento e desenvolvimento, para que se possa intervir de maneira precoce e adequada, evitando comprometimento irreversível. Diante disso, a investigação nutricional é de suma importância, uma vez que os distúrbios como: a desnutrição e a obesidade infantil podem ser diagnosticados por meio de avaliação adequada (GAÍVA et al. 2018).

Destaca-se que mesmo havendo grande objetividade na consulta de puericultura, o enfermeiro realiza a educação em saúde de forma individual, durante a própria consulta. Salienta-se que as ações educativas podem favorecer o estabelecimento do vínculo entre o enfermeiro e a comunidade, estimular as mães a participarem ativamente dos cuidados com a criança, para que compreendam como ocorre o monitoramento do crescimento $e$ desenvolvimento infantil (QUEIROZ et al. 2016).

Assim, a educação em saúde funciona como um mediador do processo de ensino-aprendizagem, por isso se torna imprescindivel a escolha dessa estratégia esducacional, visando uma assistência mais resolutiva ante a promoção e prevenção da saúde. Somado a isso, o estabelecimento do vínculo 
e a relação dos profissionais são fortalecidas e importantes para garantia de um cuidado em saúde resolutivo e integral (RAMOS et al. 2018).

Outro quesito que chama a atenção nas falas das participantes é a realização dos registros dos dados no "caderninho" e "cartãozinho" como se referem aos instrumentos, os quais são entendidos como livro de registro de enfermagem e Caderneta da Criança (CC).

"[...] anota no caderninho. (VIDA)

[...] e ela faz algumas anotações [...] pede o cartãozinho do bebê". (AMOR)

A CC é um importante documento para o acompanhamento da saúde da criança, uma vez apresenta informações sobre todo o seu histórico de saúde e deve ser utilizada para o acompanhamento em todos os tipos de serviços que a criança for assistida. A adequada monitorização e utilização deste instrumento favorece a sistematização dos dados e a comunicação efetiva entre os membros da equipe de saúde com os pais; oferece informações sobre a assistência prestada com o intuito de garantir sua continuidade, a segurança do paciente e do profissional (ABUD; GAíVA, 2016).

\subsection{Subcategoria 2: Fragilidades}

Mediante as falas das mães foi possível verificar descontentamento com a consulta, tendo em vista lacuna na investigação de alguns problemas, na continuidade do cuidado e no encaminhamento a outros profissionais quando necessário, bem como falta de estímulo a práticas saudáveis e importantes para o crescimento e desenvolvimento da criança, como a amamentação.

\footnotetext{
"Assim, não acho que tem muita coisa, eu acho que precisaria mais. Eu como mãe, eu achava que ela ia perguntar mais, que ia procurar saber mais, explicar, incentivar a pessoa em outras coisas sobre a criança. Assim, esses dias mesmo ele fez uma cirurgia, sabe? Testículo. Só que assim, eu sempre perguntava a ela, mostrava a ela, mas ela nunca encaminhou, eu que tive que correr atrás, não explicou, não me deu um encaminhamento pra mim ir atrás de um médico. Mas não tive nenhuma orientação, eu que vi e percebi e já sai correndo atrás". (SIMPATIA)

"Quando eu fui para a consulta com ela, [...] perguntou se eu estava amamentando, ai eu disse que estava mas estava dando leito também porque a menina se esguelava de fome e eu não ia deixar
} 
ela gritando de fome. Aí ela disse que eu tinha que só amamentar que era muito importante pra criança. Sendo que ela mesmo não foi dessas de orientar e dá uma força, olha você tem que fazer assim, é assim que dá certo, assim que sai mais leite. Mas infelizmente nada disso aconteceu". (PAIXÃO)

Cabe ressaltar que diversos fatores podem desencadear sentimento de insatisfação do usuário com a assistência ofertada nos serviços de saúde. $\mathrm{Na}$ consulta de puericultura é a falta de atenção na prática de prevenção para com a criança o que fundamenta o descontentamento. Diante disto, sugere-se que a rotatividade de profissionais observada na unidade de saúde da família pode limitar a formação de vínculo entre profissional e comunidade, principalmente por não ter acompanhado toda a evolução desde gestação até o nascimento e seguimento do crescimento e desenvolvimento da criança. Isso pode ser responsável pela descontinuidade do cuidado e assistência fragmentada, voltada para investigações pontuais (EINLOFT; COTTA; ARAÚJO, 2018).

É pertinente atentar que para oferta de um cuidado contínuo faz-se necessário compreender a dinâmica familiar e social, na qual a criança está inserida. Para tanto, o profissional precisa interagir com o responsável pela criança, saber quais as dificuldades, medos e contexto socioeconômico e cultural da família, para assim, ofertar um cuidado multidimensional e integral.

Corroborando esta realidade identificada na vivência das mães, pesquisa realizada no município de Maringá, evidenciou que a consulta está embasada na queixa do responsável pela criança, caracterizando o modelo biomédico, em que apenas os sintomas agudos eram levados em consideração, sem que houvesse a investigação de outras possibilidades (MALAQUIAS; BALDISSERA; HIGARASHI, 2015).

Neste contexto, vale destacar estudo de revisão o qual evidenciou que as consultas realizadas na atenção primária possuem atendimento biomédico, no qual a comunicação entre profissional e usuário é limitada, predominando o padrão informativo/investigativo, dirigido para a queixa e para a doença, excluindo a escuta e o diálogo (PERINAZZO et al. 2015).

De acordo com as falas das mães nesta pesquisa identifica-se a descontinuidade do cuidado, tendo em vista que é apontado o problema de saúde, mas não ocorre a integralização com as redes de atenção, e o 
encaminhamento a outros profissionais não acontece. Portanto, é necessário a própria mãe intervir e buscar a resolução, como no caso da necessidade da cirurgia citada na fala da mãe SIMPATIA.

Outra fragilidade envolve as orientações do enfermeiro no âmbito da atenção primária, pois devem perpassar o estímulo ao aleitamento materno exclusivo, tendo em vista os inúmeros benefícios desta prática tanto para a mãe quanto para a criança o que não foi referida no estudo em tela. Sendo assim, as orientações devem abranger a pega adequada, como evitar complicações e reduzir o desconforto relacionada a esse processo (OLIVEIRA et al. 2017).

É pertinente atentar ainda para a educação materna no processo de adesão às orientações fornecidas, especialmente na questão da amamentação e da alimentação complementar, tendo em vista que muitas mães deixam de amamentar os filhos devido existir uma série de mitos e crenças relacionados com 0 ato de amamentar que influencia diretamente na introdução precoce de outros líquidos, como os chás e a água (AMARAL et al. 2015)

$\mathrm{Na}$ vivência das participantes percebe-se a utilização de métodos impositivos como estratégias para sensibilizar as mães a ir ao serviço de saúde, como a retenção da caderneta da criança dentro do consultório de enfermagem, uma prática que pode gerar dessabores e conflitos.

\footnotetext{
"A ACS passa e prende o cartão no posto. Ela passou, pegou o cartão, disse que ia fazer uma anotação, e passou 8 dias com ele. Chegou o dia para dar a vacina aí ela disse, ei teu cartão ficou lá, que eu só vou receber quando desse a vacina lá. Que eu não podia dar em outro posto. Que se fosse em outro posto tinha que assinar um termo. Quando eu cheguei lá, não só o cartão da minha, mas de outras crianças também estavam lá, em cima da mesa da enfermeira e só podia dar lá. Acho isso totalmente errado, se elas querem cobrar tem que dar mais atenção ao paciente quando vai ao posto". (PAIXÃO)
}

A realidade merece atenção tendo em vista que sugere fragilidade na formação de vínculo do enfermeiro com as mães, o que pode ocorrer devido à 
falta de atenção no momento da consulta ou da ida do binômio à unidade de saúde, o que dificulta a busca pelo serviço.

Contribuindo com a discussão, salienta-se que o vínculo pode ser compreendido como uma relação interpessoal entre o profissional de saúde e o usuário, que ofereça confiança e responsabilidade. Sendo assim, a consulta é resolutiva quando fornece respostas aos questionamentos da família e, é baseada numa relação de confiança e vínculo entre e o profissional. Essa integração e envolvimento com a população é justamente a humanização do sistema de saúde (REICHERT et al. 2016).

Diante dessa assertiva faz-se necessário refletir este cenário, uma vez que desencadeiam repercussões para a qualidade e efetividade do acompanhamento do crescimento e desenvolvimento infantil, podendo gerar desmotivação de mães em procurar o serviço de saúde e descrédito no potencial de resolutividade da atenção, descaracterizando o serviço de prevenção e possivelmente alimentar a cultura da buscar por serviços de saúde apenas em situações de agravos e emergências já instalados (LOPES et al. 2015).

\subsection{Subcategora 3: Contribuições para integralidade do cuidado}

Para além das fragilidades encontradas, foi possível identificar que algumas mães apontam pontos positivos, destacando a continuidade no cuidado pelo enfermeiro, diante de encaminhamentos a outros seguimentos dentro da própria ESF, ou de outros serviços que foge da competência do enfermeiro.

\footnotetext{
"Ela trata a gente bem... normal, sabe? Antes não tinha, ne? Essas coisas. Eu acho bom. Acho que só... pergunta se tem alguma queixa... uma vez ela tava com febre né. tossindo, ai apareceu umas uns caroço inchado perto do ouvido, ai ela disse que era as defesas do corpo, explicou lá direitinho e mandou pro médico". (CARINHO)

"[...] também no dia que ele teve febre, ela perguntou se eu queria passar pelo médico, ou se eu queria passar pelo doutor XXX lá mesmo, me colocou na frente de todo mundo porque ele estava com febre, pra ser atendida logo. [...] vê o cartão de vacina se tem alguma coisa atrasada, se tiver atrasado ela manda ir pra menina da vacina". (DENGO)

"[...] se não teve nenhum problema de saúde, eu disse que eu tinha levado ele na pediatra, sábado agora, por que ele estava tossindo, ai ela perguntou como foi, qual a medicação que a médica tinha
} 
passado, ai eu disse, ai acho que foi só... sempre ela pergunta o que ta acontecendo comigo e com ele". (APEGO)

Considerando a integralidade como princípio do Sistema Único de Saúde SUS, salienta-se que serviços de puericultura deve considerar as necessidades específicas da criança, de forma organizada e em rede com outros serviços de saúde em diferentes complexidades, sendo condição indispensável para a continuidade do cuidado. Para tanto, é necessário um olhar para as equipes de saúde da família no intuito de sensibilizá-las e instumentalizá-las para implementação de seu processo de trabalho no contexto da atenção primária à saúde (PERUZZO et al. 2018).

O trabalho em equipe multiprofissional é muito importante, pois caracteriza avaliar a necessidade de saúde de maneira extremamente holística, em que cada profissional poderá dar a sua contribuição e visualizar a criança de forma geral. Essa estratégia tem potencial até para permitir uma melhor interação entre os profissionais, favorecendo a organização do processo de trabalho na Atenção Primária à Saúde (APS). Permitindo um atendimento integral e resolutivo, uma vez que acontece a troca de informações e a busca do melhor tratamento (MALAQUIAS; BALDISSERA; HIGARASHI, 2015).

\section{Conclusão}

A partir dos resultados obtidos do estudo, é possível verificar que o objetivo foi ratificado ao passo em que evidenciou a compreensão acerca da consulta de puericultura em enfermagem de acordo com a vivência de mães. Nesse sentido a consulta de puericultura em linhas gerais foi classificada como rápida, objetiva, com foco apenas na queixa das mães, a formação de vínculo se mostra ineficaz, entretanto algumas participantes referem continuidade do atendimento em outros segmentos da atenção básica.

Nessa perspectiva é necessário se apropriar da percepção dos responsáveis pela criança acerca da consulta de puericultura sob a forma de avaliação do serviço que está sendo ofertado, tendo em vista que esse mecanismo de feedback trará inúmeras modificações e melhorias ao serviço de saúde. De acordo com os resultados, a consulta de puericultura deve ser 
planejada e ofertada aos moldes da política de humanização do SUS, no qual a fragilidade do atendimento foi considerada o dado mais frequente.

As informações obtidas dão suporte a necessidade de conhecimento sobre as práticas realizadas pelos enfermeiros na consulta de puericultura, um reflexo do atendimento na voz das usuárias. Sendo assim, se faz necessário uma ampla divulgação destes resultados para que estudos semelhantes possam ser realizados em outras realidades.

\section{Referências}

ABUD, S. M.; GAÍVA, M. A. M. Análise do preenchimento dos dados sobre gravidez, parto, puerpério e recém-nascido na caderneta de saúde criança. Rev Soc Bras Enferm Ped, v. 16, n. 1, p. 11-20, 2016. Disponível em: <https://sobep.org.br/revista/images/stories/pdf-revista/vol16-n1/vol_16_n_1-artigo-depesquisa-1.pdf >. Acesso em: 02 Jun. 2018.

AMARAL, L.J.X. et al. Fatores que influenciam na interrupção do aleitamento materno exclusivo em nutrizes. Rev Gaúcha Enferm, São Paulo, v. 36, n. esp., p. 127-134, 2015. Disponível em: < https://www.scielo.br/pdf/rgenf/v36nspe/0102-6933-rgenf-36spe-0127.pdf>. Acesso em: 3 Out. 2020.

BRASIL. Ministério da Saúde. Portaria no 1.130 de 5 de agosto de 2015. Brasília, DF, 2015.

CARVALHO, E. B.; SARINHO, S. W. A consulta de enfermagem no acompanhamento do crescimento e desenvolvimento de crianças na estratégia saúde da família. Rev Enferm UFPE, v. 10, n. 6, p. 4804-4812, 2016. Disponível em: <file:///C:/Users/Arthur/Downloads/11259-25409-1-PB.pdf>. Acesso em: 31 Ago. 2020.

EINLOFT, A. B. N.; COTTA, R. M. M.; ARAÚJO, R. M. A. Promoção da alimentação saudável na infância: fragilidades no contexto da Atenção Básica. Rev Ciência \& Saúde Coletiva, v. 23, n. 1, p. 61-72, 2018. Disponível em: <http://www.scielo.br/pdf/csc/v23n1/1413-8123-csc-23-01-0061.pdf>. Acesso em: 10 Jun. 2018.

GAíVA, M. A. M. et al. Avaliação do crescimento e desenvolvimento infantil na consulta de enfermagem. Rev Av Enferm, v. 36, n. 1, p.9-21, 2018. Disponível em: http://www.scielo.org.co/pdf/aven/v36n1/0121-4500-aven-36-01-00009.pdf. Acesso em: 05 Jun. 2018.

GÓES, F.G.B. et al. Contribuições do enfermeiro para boas práticas na puericultura: revisão integrativa da literatura. Rev Bras Enferm, v. 71, p. 2974-2983, 2018. 
Disponível em: <https://www.scielo.br/pdf/reben/v71s6/pt_0034-7167-reben-71-s62808.pdf>. Acesso em: 31 Ago. 2020.

GOMES, L.T.S.; SILVA JÚNIOR, S. I. Processo de trabalho em enfermagem na saúde da família: revisão da literatura. Rev APS, v. 18, n. 3, p. 390-397, 2015. Disponível em: https://aps.ufjf.emnuvens.com.br/aps/article/view/2123/902. Acesso em: 07 Jun. 2018.

IBGE - Instituto Brasileiro de Geografia e estatística. Censo demográfico. 2017. Disponível em: <https://cidades.ibge.gov.br/brasil/pb/cuite/panorama>. Acesso em: 10 Jun. 2018.

LOPES, A. S. et al. O acolhimento na atenção básica em saúde: relações de reciprocidade entre trabalhadores e usuários. Rev Saúde Debate, v.39, n.104, p. 114123, 2015. Disponível em: <https://www.scielo.br/pdf/sdeb/v39n104/0103-1104-sdeb39-104-00114.pdf>. Acesso em: 15 Jun. 2018.

MALAQUIAS, T. S. M.; BALDISSERA, V. A. D.; HIGARASHI, I. H. Percepções da equipe de saúde e de familiares sobre a consulta de puericultura. Rev Cogitare Enferm, v. 20, n. 2, p. 368-375, 2015. Disponível em:

<https://www.revistas.ufpr.br/cogitare/article/view/40012>. Acesso em: 29 Jun. 2018.

MAISSIAT, G. S. et al. Contexto de trabalho, prazer e sofrimento na atenção básica em saúde. Rev Gaúcha Enferm, v. 36, n. 2, p. 42-49, 2015. Disponível em:

$<$ https://www.scielo.br/pdf/rgenf/v36n2/pt_1983-1447-rgenf-36-02-00042.pdf>. Acesso em: 13 Jun. 2018.

MONTEIRO, F. P. M. et al. Crescimento infantil: análise do conceito. Rev de APS, v. 25, n. 2, p. 1-9, 2016. Disponível em: <https://www.scielo.br/pdf/tce/v25n2/pt_01040707-tce-25-02-3300014.pdf>. Acesso em: 22 Jun. 2018.

MINAYO, M. C. S. O Desafio do Conhecimento: pesquisa qualitativa em saúde. 10. ed. rev. e aprim. São. Paulo: Hucitec, 2006.

OLIVEIRA, C. M. et al. Promoção do aleitamento materno: intervenção educativa no âmbito da estratégia de saúde da família. Enferm Rev, v. 20, n. 2, p. 99-108, 2017. Disponível em:

<https://periodicos.pucminas.br/index.php/enfermagemrevista/article/view/16326>. Acesso em: 14 Jun. 2018.

PERINAZZO, J. et al. A atuação do profissional biomédico na atenção primária à saúde: desafios na formação. Rev Saúde Integrada, v. 8, n. 15, p. 1-9, 2015.

Disponível em: <https://local.cnecsan.edu.br/revista/index.php/saude/article/view/246> Acesso em: 23 Jun. 2018.

PERUZZO, H. E. et al . Os desafios de se trabalhar em equipe na estratégia saúde da família. Esc Anna Nery, v. 22, n. 4, e20170372, 2018. Disponível em: 
https://www.scielo.br/scielo.php?script=sci_arttext\&pid=S1414-

81452018000400205\&lng=en\&nrm=iso . Acesso em: 02 Dez. 2020.

QUEIROZ, M. V. O. et al. Grupo de gestantes adolescentes: contribuições para o cuidado no pré-natal. Rev Gaúcha Enferm, v. 37, n. esp., p. 1-7, 2016. Disponível em: $<$ https://www.scielo.br/pdf/rgenf/v37nspe/0102-6933-rgenf-1983-14472016esp20160029.pdf>. Acesso em: 12 Jun. 2018.

RAMOS, C.F.V. et al. Práticas educativas: pesquisa-ação com enfermeiros da Estratégia de Saúde da Família. Rev Bras Enferm, v. 71, n. 3, p. 1211-1218, 2018. Disponível em: <https://www.scielo.br/pdf/reben/v71n3/pt_0034-7167-reben-71-031144.pdf>. Acesso em: 31 Ago. 2020.

REICHERT, A. P. S. et al. Vínculo entre enfermeiros e mães de crianças menores de dois anos: percepção de enfermeiros. Rev Ciência e Saúde Coletiva, v. 21, n. 8, p. 2375-2382, 2016. Disponível em: <https://www.scielo.br/pdf/csc/v21n8/1413-8123-csc21-08-2375.pdf>. Acesso em: 23 Jun. 2018.

SOARES, D. G. et al. Implantação da puericultura e desafios do cuidado na estratégia saúde da família em um município do estado do Ceará. Rev Bras de Promoção a Saúde, v. 29, n. 1, p. 132-138, 2016. Disponível em: <https://periodicos.unifor.br/RBPS/article/view/3713>. Acesso em: 13 Jun. 2018.

VIEIRA, D. S. et al. A prática do enfermeiro na consulta de puericultura na estratégia saúde da família. Rev Contexto enferm, v. 27, n. 4, 2018. Disponível em: https://www.scielo.br/pdf/tce/v27n4/0104-0707-tce-27-04-e4890017.pdf. Acesso em: 13 Abril. 2021. 